\title{
An Evaluative Look: Mississippi's Response to the Olmstead V. L. C. Case Twenty-one Years Later
}

Bridgette Stasher Booker PhD, RHIA, CHTS-IM, CPAR, MCCT.

Health Information Management, Alabama State University, 915 South Jackson Street Montgomery, 36104, United States.

\author{
Article Details \\ Article Type: Research Article \\ Received date: $14^{\text {th }}$ June, 2020 \\ Accepted date: $10^{\text {th }}$ July, 2020 \\ Published date: $15^{\text {th }}$ July, 2020
}

"Corresponding Author: Dr. Bridgette Stasher-Booker PhD, RHIA, CHTS-IM, CPAR, MCCT, Health Information Management, 915 South Jackson Street Montgomery, 36104, United States. E-mail: bbooker@alasu.edu

Citation: Booker, B. S. (2020). An Evaluative Look: Mississippi's Response to the Olmstead V. L. C. Case Twenty-one Years Later. J Rehab Pract Res 1(2):108. https://doi.org/10.33790/jrpr1100108

Copyright: $\odot 2020$, This is an open-access article distributed under the terms of the Creative Commons Attribution License 4.0, which permits unrestricted use, distribution, and reproduction in any medium, provided the original author and source are credited.

\section{Abstracts}

Our society still struggles with the notion that people with disabilities are less human and, therefore, are not fully eligible for the opportunities and services, which are available to "normal" people as a matter of right. Nearly one in five U.S. adults live with a mental illness (46.6 million in 2017). Mental illnesses include many different conditions that vary in degree of severity, ranging from mild to moderate to severe. Mental illness statistics may double by 2030 and Mississippi must have a plan of action.

The problem is defined as institutionalized individuals with disabilities may benefit more through services offered in their own community. The institutional long-term care situation arose in June 1999 when the U.S. Supreme Court ruled in L.C. \& E.W. vs. Olmstead. It is a violation of the Americans with Disabilities Act for states to discriminate against people with disabilities by providing services in institutions, when one community-based setting is more appropriate. The Court endorsed the notion that a state can be required to fund community placements by moving resources from institutions to the community.

The right to community care extends only to those who can handle its services. Although the United States mental health system has swiftly diverted from institutional based services to community services, Mississippi has exemplified a favorable shift in community services for persons with disabilities.

Key words: Mental Health, Reasonable Accommodation, Mental Illness

\section{Introduction}

Twenty-one years after the Olmstead case, Mississippi is still in violation of Title II of the Americans with Disabilities Act. According to District Judge Carlton W. Reeves of the Southern District of Mississippi, "States from every corner of the country have struggled to provide adequate mental health care services. Mississippi has its own unique challenges due to its rural nature and limited funding [1]." Mississippi's woes began in 1999 with the litigation of Olmstead vs. LC, which focused on long-term services, and supporting systems that promote community integration, independence, and individual choice that was changing and needed improvement [2]. The United States Supreme Court recognized the inappropriate isolation of individuals within institutions is unsuitable and discriminatory. The isolation and segregation of individuals with disabilities is a serious and pervasive form of discrimination under the ADA [3].
The national campaign for deinstitutionalization movement began over sixty years through the efforts of the executive and judicial branches of government. The movement pledge was to extend the civil rights of the disabled and upgrade the conditions within institutions. Mental health directors around the country responded by building community mental health centers. The state's Medicaid Program allocates funds to community health centers. Olmstead is not a case based on the Medicaid statues and regulations administered by the federal government. Rather, Olmstead establishes that state Medicaid programs must operate in ways that comply with the American with Disability Act. The Olmstead decision advances the civil rights of people with disabilities and recognizes that Medicaid represents the largest source of public funding for both institution and non-institutional services for persons with disabilities [4]. A solution to the Olmstead decision can be interpreted in terms of the Home and Community-Based waiver (HCBS) program. The intent of the HCBS waiver program is to slow the growth of Medicaid spending and prevent an increase in cost associate with individuals integrating into the community [5].

\section{Aim of the Study}

This study will determine if home and community-based services are utilized more than institutional care. The determination will be relevant to mental health agencies by analyzing expenditure trends for both community and institutional care facilities.

\section{Discussion}

\section{Medicaid's Perceived Role}

The Medicaid program, by law, favors institutional care for the elderly and disabled individuals who need help with daily living activities [6]. The Medicaid statute is a congressional policy, which appears to show preference to institutional treatment [7]. Medicaid statues require state programs to provide institutional services to all eligible individuals as a mandatory benefit and permits states to make services available in the community as an optional benefit [8]. Medicaid is a federally funded program that purchases basic health and long-term care services on behalf of 51.5 million Americans [9]. Although nearly 75 percent of Medicaid beneficiaries are children and adults, these groups account for less than 30 percent of spending on benefits.

Medicaid is the federal government's third largest domestic program: only Social Security and Medicare are larger [10]. According to Kaiser, Medicaid pays almost half of all long-term cost [11]. The elderly 
and disabled make up only $25 \%$ of Medicaid beneficiaries, however this constitutes at least 70 percent of expenditures [12]. The cost of long-term care is estimated to be $55 \%$ of spending for benefits. Wiener and Stevenson conducted a study of 13 long-term care facilities and discovered Medicaid made up 54 percent of the total Medicaid spending for long-term care [13]. The cost of Medicaid in FY 2018 is estimated to be about $\$ 592$ billion, with the federal government paying $\$ 377$ billion and the states as much as $\$ 222$ million [14]. For the state of Mississippi, the federal government spent $\$ 4$ billion $(76 \%)$ and the state spent $\$ 1$ billion $(24 \%)$. State Medicaid programs can provide services:

1. Through home and community-based service waivers:

2. Through one of several optional state plan services, and

3. Through the home health benefit.

In 2018, Medicaid coverage increased to 97 million low-income Americans and is expected to rise [15]. A breakdown of the above fact reveals Medicaid served 32 million children, 28 million adults (mostly in low-income working families), 6 million seniors, and 9 million people with disabilities [16].

\section{Implications for Home and Community-based Services}

The facts within the Olmstead case indicate states agreed to furnish mental health care through home and community-based waiver program but, in fact, the state of Georgia operated their program at only a third of its federally approved size (approximately 700 placements available fact specifically noted by the Court in dismissing the state's assertions regarding Medicaid's institutional bias) [17]. During the 2000, National Conference of State Legislators, the Olmstead ruling has relevance to the waiver program because it requires states to maintain waiting lists, which place people back into the community in a reasonable pace [18]. According to Mississippi Medicaid statue, the state must provide institutional services to all eligible individuals as a mandatory benefit and states are to make services available in the community as an optional benefit [19]. Most states provide community-based services through their 1915 Home and Community-based services (HCBS) waivers that allow states to be specific populations and geographic locations. Every state has at least one HCBS waiver, except Arizona, which provides similar types of services through a 115 waiver.

Medicaid's home and community waiver program are the fire that fuels the Olmstead debate. Nationally, home and communitybased waiver programs for the elderly and disabled serve $1,847,369$ recipients, in contrast with $1,036,833$ in nursing homes. In 2001, at least ninety-one percent of Mississippi's Medicaid long-term care funding was expensed to institutional care; only 9 percent went to home and community-based services (HCBS) [20]. Those percentages had hardly changed since 1994, when the allocations were 97 percent institutional to three percent HCBS [21]. Thus, 64 percent of Medicaid recipients who are elderly and disabled longterm care clients received some type of home and community-based services [22]. Currently, Mississippi has five home and communitybased waiver programs. The Elder and Disabled Waiver, the Independent Living Waiver, the Mentally Retarded/Developmentally Disabled Waiver, the Assisted Living Waiver, and the TBI/SCI Waiver [23]. Similarly, about the same percentage of individuals with mental retardation/developmental disabilities (MR/DD) receiving Medicaid long-term care services receive these services in home and community-based settings, rather than Intermediate Care Facilities [24]. In Mississippi, three-quarters of all home and community-based waiver spending is for services for individuals with MR/DD [25].

According to the federal government, in 1999 Mississippi was not complying with the federal government rule, which seeks to define community placement to be no more than six people to a dwelling. Several states have chosen the Medicaid 1915(c) waiver option as their primary mechanism for funding home and community-based services for aged/disabled, including Oregon, Washington, Wisconsin,
Colorado, and Minnesota. The monitoring of Home and Community-Based Services program trends will assist policy makers in addressing unmet needs and raising consumer demands for home and community-based services [26]. Without proper monitoring of HCBS waivers, waiting lists will increase for people with disabilities [27].

States may request to amend their current HCBS waiver program to include additional participants. States that do so are still required to demonstrate the continued cost-neutrality of those programs [28]. According to the Centers for Medicaid and Medicare Services, most states have found that aggregate waiver programs continue to demonstrate cost neutrality even with additional participants [29]. Unfortunately, most states do not have a centralized mental health system capable of providing checking and balances to its programs. At the present, there is no comprehensive health information exchange system of long-term care for the disable in the United States. Services are provided through a multitude of programs and agencies with each acting independently of the others, with no centralized responsible or coordination [30]. Financing is the biggest issue in long-term care; the primary gap in the health care system is the lack of coverage for long-term care. On April 29, 2002, President George W. Bush assembled the Freedom Commission on Mental Health to "treat mental illness with the same urgency as physical illness, [31]" restructure the national health care system. They described the

"Health care delivery is like a house of cards. You can add cards at the bottom: Medicaid expansions. You can add cards at the top: Medicare catastrophic. It is still a house of cards. Now a house of cards can stand in a stillroom, but it cannot stand in a wind, and winds of change everywhere are blowing in the direction of health care delivery-the wind of demographic change, the wing of rising cost, the wind of consumer dissatisfaction. Soon the house of cards wills collapses under the pressure of these winds of change" [32].

The Obama Administration recognized the "winds of change" with the allocation of $\$ 100$ million in mental health funding to expand service delivery in community health settings and rural areas. Under the Affordable Care Act, a record \$50 million touched the lives. At least 200 community health centers were able to provide reasonable accommodation to individuals living with mental illness and/or substance use disorders (Nation Council for Behavioral 2013) [33]. Currently, President Trump's 2021 budget calls for over $\$ 1$ trillion in cuts of Medicaid and the ACA. This could have a negative impact on Mississippi's effort to comply with the Olmstead Act.

\section{Summary of Findings}

The Mississippi Medicaid eligible ID/DD population is forecasted to increase in terms of expenditure and population. Based on the 20year study the ID/DD populations as related to those persons fitting the criteria of state expenditure aged, blind and disabled are expected to increase as a result of increase community expenditures.

In terms of Medicaid's role in the Olmstead decision, federal and state proportional share funding is fundamental in understanding community integration. Although the federal government plays no direct role in the Olmstead case, its administering of funds help supports health care coverage in Mississippi. Both state and federal funding of Medicaid is statistically significant. The decreases/ increases in federal funding are evident in the political aspects of how Mississippi addresses the issues.

According to the Mississippi PEER Report the state has devoted significant resources to the public mental health system. It ranks second in the southeastern United States and nineteenth in the nation in annual per capital expenditure for services [34]. In the current report community-based services is define as serving one to six residences in a nonrestrictive setting. On the other hand, Mississippi defends community-based setting as more than 6 persons living in a less restrictive setting. Although, this study illustrates community-based 
services being prevalent years before the Olmstead decision, the PEER Report suggest the services are equivalent to institutional services. According to the PEER Report, Mississippi has focused primarily on funding institutional based services for both mental illness and mental retardation (Developmentally Disabled). In Fiscal Year 2006, "Mississippi fiscal efforts for delivering services for (ID/DD) was the highest in the nation and more than double the average fiscal effort of other southeastern states [35]." In each study the Mississippi community-based population is defined in terms of the Intellectually Disabled and Developmentally Disabled population. Although slowly increasing in numbers the study shows strong growth before and after the Olmstead decision. Unfortunately, the funding for community is much less than psychiatry facilities. Further analysis of the community population concluded that years before the Olmstead decision, Mississippi was promoting community integration at a rate like the federal standards. The distribution of community population can be viewed into two settings: intermediate care facilities and home and community-based waivers. Both the intermediate care facilities and home and community-based waiver programs are optional Medicaid services for persons with ID/ DD diagnoses. Section 1905 (d) of the Social Security Act created intermediate care facilities to fund institutions with four or more beds for people with developmental disabilities or other related conditions [36]. Home and community-based waivers provide home health care as well as services within the community. This study analyzed the latter choice of services to promote community integration. The data analysis revealed that both intermediate and home and communitybased care services are flourishing at a steady rate before and after the Olmstead decision. Meanwhile, the institutional population has declined, although state per diem is steady increasing over years. This increase may be associated with political, economic and social factors. Home and community-based services for one to six persons has sharply increased over the 15 -year study period at a rapid rate before and after the Olmstead decision. Surprisingly, community expenditures are increasing at about 35 million a year, while institutional expenditures are 95 million. Community expenditures are about 3 times less than institutional expenditures. Community expenditures are expected to close the gap on institutional expenditures.

In conclusion, the research questions analyzed within this study concluded that significant relations exist among expenditures, population, and community and state facilities. The outcomes of the analysis found significant expenditure differences exist between the Medicaid eligible populations. Multiple regression analysis revealed that the disable population correlates to the increases in funding, allowing this variable to be statistically significant towards community expenditures. In addition, a strong significance was recorded in state and federal funding as well as community-based populations. The following hypotheses were analyzed and concluded that:

- The implementation of the Olmstead decision has had an impact on Mississippi's funding of community-based health care.

- The implementation of the Olmstead decision has had an impact on Mississippi's funding of institutional mental health care.

- Arelationship exists between Mississippi funding of communitybased services and state psychiatric facilities.

\section{Conclusions and Recommendations}

The purpose of this study was to evaluate Mississippi's response to the Olmstead decision before and after its rendering. Variables used to evaluate this issue was Mississippi Medicaid population and funding, state and federal matching funds as well as institutional and community population and expenditures. Each variable was tested to determine if they were statistically significant against time (years).

A major implication of this study is that the Mississippi Department of Mental of Health is committed to the needs of persons with disabilities and it is evidenced in their response to integrating disabled persons back into the community. Data show the department has established community-based services prior to the 1999 United States Supreme Court, Olmstead v. L.C decision. In addition, the department has slowly reduced their institutional population.

Mississippi has concentrated more funding towards community placement, but not at a rate of recommended by the Department of Justice. Both community population and expenditure gaps are solely closing, which reflects a favorable response. These findings were consistent with the 2008 Mississippi Joint Legislative Performance Evaluation and Expenditure Review report. Mississippi is making process in terms of community integration for persons with disabilities.

However, the limited scope of this study suggests that community integration is favorable to the intellectual and developmentally disabled populations only. Data were not accessible to study Mississippi's diverse mentally ill populations as well as their complete budget and expenditures. It is highly recommended that Mississippi's mental health data becomes more accessible not only to policymakers, but to consumers, as well as researchers whose quest is to eliminate mental health disparities. The accessibility of the data would expand the scope of study to include all disabled populations as well as a holistic view of how community-based settings are utilized. Future studies on community integration in Mississippi will add relevance to existing and emerging research to determine if funding differences exist between community and institutional facilities.

The finding of this research and the absence of data storages to ensure reliability in Mississippi's mental health programs and services should be revisited by both federal and state officials. A mere reporting of high number of disabled persons, barriers, and budget shortfalls should not be the prime factor for allocating additional funding, but the analysis of data and the interpretation of trends should be considered necessary to determine if a program is effectively working for the affected population. In particular, the following recommendations are offered: 1). Creating a Multidisciplinary collaboration, 2). Administering strong discharge plans, 3). Exploring federal housing policies, and 5). Creating a centralized mental health information exchange program.

\section{Recommendations}

The Mississippi Department of Mental Health's mission is to support a better tomorrow by making a difference in the lives of Mississippians with mental illness, substance abuse problems and intellectual or developmental disabilities one person at a time. This statement can become more effective through the collaboration of multiple state agencies whose objective is to pursue, promote, support and prevent mental health disparities. Mississippi has multiple state and local agencies commissioned with the task of advocating for the protection and stability of disabled persons to live healthy and safe lives. Unfortunately, these entities function in silos, which fail to form a strong alliance that can serve a large array of consumers diagnosed with mental illness. Although this recommendation was prescribed within the Mississippi Access for Care plan, it has remained inactive. With the support of state regulatory agencies, efforts may be in order to establish this type of collaboration.

A strong discharge plan is also recommended to secure a strong continuum of care for persons with disabilities. Much attention is given to reducing lengths of stay in psychiatry hospitals, with primary goals being immediate diagnosis, resolution of the crisis as well as an applicable discharge plan [38]. The discharge process and plans are primary tools for successfully transitioning consumers from the hospital to the next health care setting. Proponents believe a poor transition can be devastating for the patient as well as the family. Therefore, it's important to improve discharge planning and, by 
doing so may reduce readmission rates. The Olmstead decision establishes the foundation for state of Mississippi to prepare adequate discharge alternatives for persons ready to exit institutional settings. A non-structured discharge plan can pose a barrier for consumers who seek to live independent lives. Discharge interventions that assess the need for social support and provide access and services have the potential to reduce chronic re-hospitalization. Opponents fear the current fiscal environment favors shortened lengths of stay may leave vulnerable consumers at risk for adverse outcomes upon discharge, especially for those discharged home that are unprepared to accommodate their rigid health care needs. Written strategies for improving the discharge plan have a significant impact on the psychiatric hospitals as well as the community.

Currently, the socioeconomic implication of the housing crisis is characterized by a deteriorating stock market, extensive federal budget cuts and rigorous limitations on state budgets suggest Mississippi and local government officials must invoke innovate, creative and strategic ideas to meet the housing needs of persons with disabilities. Mississippi has already developed a blueprint of action but has failed to develop vigorous legislation that would position these actions into motion to transition persons with mental illness back into the community. This blueprint consists of impressive goals and objectives located within the Mississippi Access to Care Plan. The Mississippi Access to Care creators strategically established a to allocate 5 to 10 percent of all state housing funds granted to cities and counties to be used for individuals with disabilities." In addition, the transitioning of persons with disability into the community could be obtained by utilizing the National Affordable Housing Trust Fund (H.R. 2895). This policy seeks to address the shortage of housing that is affordable by creating permanent funds to finance the construction of independent living. The lack of federal subsidies, the lack of sensible state housing investment has made it difficult for the Mississippi Department of Mental Health to secure adequate funding for the development of adequate housing for the disabled. In order to provide extensive community-based services to persons with disability a strong collaboration with multi-state and federal agencies must be secured. mechanism to generate capital available for the construction, acquisition, and development of independent housing for the disabled. Through the collaboration of public housing authorities, local and state governments, public and private entities Mississippi can truly transition all persons with disabilities back into the community. Finally, these recommendations cannot be fully executed without a centralized mental health warehouse of data. A centralized data warehouse will eliminate biased opinions and mistrust of our current mental health system and align our state with technological advances capable of storing and tracking resource and expenditure trends to alleviate the mission and future of mental health care.

\section{Prospects for Future Research}

A follow-up of community and institutional funding and population trends should be conducted by both state and local community mental health centers to determine if adequate funding has been allocated to mental health programs. Future studies will add to existing research and will illustrate the positive works of the Mississippi Department of Mental Health through the analysis of data. The collection of data will show how the department of mental health collects data to establish benchmarks. By regular monitoring of mental health data collected we will be able to build a stronger model of how the general behavior of the system functions. This will provide valuable comparisons and contrasts when we study the mental health system in more detail. By establishing benchmark data on patterns will indicate how typical data are collected for time periods and forecast long-term changes within the system. solution which encourages the Mississippi Development Authority

The State of Mississippi must also develop innovative financial

This research is important because it contributes to the performance and evaluation of Mississippi public policy affecting persons with disabilities. The evaluation of Mississippi's mental health program and expenditures provides a blueprint for the distribution of resources and services established to promote independence and healthy living. Public policy evaluation can direct as well as guide policy makers in developing effective polices. The analysis determined that Mississippi exhibits a favorable response to the Olmstead decision. Additional research has the potential to demand for positive communication and storage of data to develop solutions to effectively treat persons suffering from emotional and physical disabilities.

Conflicts of interest/Competing interests: Authors report no conflict or competing interest.

\section{References}

1. Cornell University Law School. (1999). Legal Information Institute. Justice Thomas dissenting. Olmstead v. L.C. (98-536) 527 U.S, 581:138 F. 3d 893, affirmed in part, vacated in part, and remanded.

2. Ginsburg, Judicial Voce, supra note 5, at 1198. (1999). For a later endorsement of a similar orientation toward social change litigation form the legal academy, see generally Cass R. Sunstein, One Case at a time: Judicial Minimalism on the Supreme Court.

3. Olmstead v. L.C. by Ziming, 527 United States 581 (1999). (No. 98-536), unavailable at 1999WL 54623. Opinion of Stevens, J. Supreme Court of the United States No. 98-536.

4. Pennsylvania Department of Corrections v. Yeskey. (1998). 524 United States 206.

5. Randon, Bragdon., \& Petitioner v, SA, et al. (1998). 524 United States 624 June 25.

6. Ruth, B. G. (1992). Speaking in a Judicial Voice, 67 N.Y.U. Law Review 1185, 1205-09. [hereinafter Ginsburg, Judicial Voice] (publishing the revised text of Justice Ginsburg's 1993 James Madison Lecture on Constitutional Law at New York University School of Law).

7. Americans with Disability Act of 1990. U.S. Public Law 336, 2d session (July 26) sec 2, sec. $3 \sec 2$; 42 USC $\S 12101$.

8. Hilderbrand, D. H., and Ott, R. L. (1998). Statistical Thinking for Managers: Fourth Edition.

9. Lewin, B.L., and J, Petrila. (Eds.) Mental Health Services: A public health perspective. (pp. 301-319). New York: Oxford University Press.

10. Mui, Ada C., Choi, Namkee G., and Monk, Abraham .(1998). Long-term care and Ethnicity Westport, Conn: Auburn House

11. Nemeth, C., and Owens, P. "Making groups more effective: The value of minority dissent," in M.A. West, editor, Handbook of Wok Group Psychology, Chichetser Wiley.

12. Posavac, Emil., and Carey, Raymond. (1992). Program Evaluation: Methods and Case Studies. Prentice Hall: New Jersey.

13. Smigel, Erwin O. (1971). Handbook of the Study of Social Problems. Rand McNally Company, Chicago.

14. United States Board on Health Promotion and Disease Prevention. (2002). The Future of the Public's Health in the 21st Century.

15. Kaiser Commission on Medicaid and the Uninsured. (2002). The Medicaid Resource Book. Washington, D.C.

16. Kaiser Family Foundation. (2007). State Health Facts. Behavioral Risk Factor Surveillance System. The Center for Disease Control and Prevention (CDC' Behavioral Risk Factor Surveillance System, (BRFSS). 
17. United State Census Bureau. (1997). McNeil, Jack. "Americans with Disabilities: Household Economic Studies Current Population". United States Department of Commerce. Issued.

18. United States Census Bureau. "Disability Status (2000)." United States Department of Commerce. Washington, D.C. March 2003.

19. United States Department of Health and Human Services. (2004). Centers for Medicare and Medicaid Services, Mark B. McClellan, M.D. Ph. D.

20. United States Department of Health and Human Services. (2004). Centers for Medicare and Medicaid Services. "CMS Encourages states to give Medicaid Beneficiaries ore control over the long-term care services they receive."

21. United States Department of Health and Human Services. (2006). Department of Mental Health. Washington, D.C.

22. United States Health and Human Services. (1980). Center for Medicaid and Medicare. Mississippi Medicaid Law 42 CFR 433 32.

23. Ajalat, C. M. (1999). "Recent Developments.” Harvard Journal of Law and Public Policy, 22.

24. Hogan, M. F. (2003). New Freedom Commission Report: The President's New Freedom Commission: Recommendations to Transform Mental Health Care in American, https://doi. org/10.1176/appi.ps.54.11.1467

25. Kaiser Commission on Medicaid and the Uninsured (2000). "The Olmstead Decision: Implications for Medicaid". Washington, D.C.

26. Ladd, R.C., Kane, R. L., and Kane, R. A. (1996). "State Long Term Care Profiles Report, 1996." University of Minnesota School of Public Health, Division of Health Services Research and Policy.

27. Lakin, K.C., and Stancliffe, R.J. "Cost-Effectiveness of Different Models of Community Support

28. LaPlante, Mitchell, Kaye, Steve, Kang, Taewoon, Harrington, Charlene. (2004). "Unmeet Need for Personal Assistance Services: Estimating the Shortfall in Hours of Health and Adverse Consequences," Journals of Gerontology: Social Sciences 59, no. 2: S98-S108.
29. Lutzkt, Dyrven, Aleckih, Lisa Maria, Dufy, Jennifer and Neil, Christina (2000). "Review for the Medicaid 1915(c ) Home and Community Based Services Waiver Program Literature and Program Date: Final Report, Department of Health and Human Services Health Care Financing Administration.

30. Medical Education Committee GAP. (1990). "Health Care Reform and Postgraduate Psychiatric Education." Academic Psychiatry 23:1-8. See also, Meyer R. E, Satsky SM: Managed care and the role and training of psychiatrists. Health Affairs (Millwood) 1995; 14:65-77.

31. Miller, Vic., and Schneider, Andy. (2004). "The Medicaid Matching Formula: Policy Considerations and Options for Modification".

32. Mississippi Joint Legislative Committee on Performance Evaluation and Expenditure Report. (2008). "Planning for the Delivery of Mental Health Services in Mississippi: A Policy Analysis."

33. National Council on Disability, (2004). "Strategies to Improve Access to Medicaid Home and Community Based Services: Senate Questions and National Council on Disability Response for the Record".

34. Reester, Heidi, Missmar, Raad, and Tumlinson, Anne. (2004). "Recent Growth in Medicaid Home and Community-Based Service Waivers prepare for the Kaiser Commission on Medicaid and the Uninsured.

35. Sommers, A., Cohen, M., and O'Malley, M. (2006). "Medicaid's long-term care beneficiaries: An analysis of spending patterns" Issue Brief\#7576. Washington, D.C. : Kaiser Family Foundation.

36. Steelman, Deborah. (1990). Executive Director Wire. New York: National League for Nursing.

37. United States Department of Health and Human Services, Office of the Assistant Secretary of for Planning and Evaluating. "State Long Term Care: Recent Developments and Policy Directions, Appendix A.

38. Wiener, J., and Stevenson, D. G. (1998). "State Policy on LongTerm Care for the Elderly". 